\title{
sciendo
}

\section{BODY TEMPERATURE RESPONSES AND HAIR CORTISOL LEVELS IN DAIRY HOLSTEIN COWS FED HIGH- AND LOW-FORAGE DIET AND UNDER WATER DEPRIVATION DURING THERMAL-HUMIDITY EXPOSURE}

\author{
Jalil Ghassemi Nejad, Bae-Hun Lee, Ji-Yung Kim, Befekadu Chemere, Si-Chul Kim, Byong-Wan Kim, \\ Kyu-Hyun Park, Kyung-Il Sung*
}

College of Animal Life Sciences, Kangwon National University, 24341 Chuncheon, Republic of Korea •Corresponding author: kisung@kangwon.ac.kr

\begin{abstract}
Body temperature responses and hair cortisol levels in dairy Holstein cows fed high- and lowforage diet and under water deprivation during thermal-humidity exposure (THE) were evaluated. Two experiments (Exps.) were conducted between July and September 2012 and 2013 for $64 \mathrm{~d}$ and $74 \mathrm{~d}$, respectively. First, twenty dairy Holstein cows $(90 \pm 30 \mathrm{DIM} ; 37.2 \pm 1.7 \mathrm{I} \mathrm{milk/d}$, $620 \pm 75 \mathrm{~kg} \mathrm{BW})$ were used. The practical forage:concentrate $(\mathrm{F}: \mathrm{C})$ ratios in the low forage (LF) and high forage (HF) group were 44:56 and 56:44, respectively, while they were designed to be 40:60 and 60:40. Second, thirty dairy cows $(53.5 \pm 30.4 \mathrm{DIM} ; 41.7 \pm 1.5 \mathrm{I} \mathrm{milk} / \mathrm{d}, 650 \pm 53 \mathrm{~kg} \mathrm{BW})$ were allotted into two groups of free access to water (FAW) and $2 \mathrm{~h}$ water deprivation (2hWD) following feeding. The animals were subjected to having the hair cut (1 to $2 \mathrm{~g}$ ) from their foreheads at the same time (12:00 h) twice at the beginning (prior to the beginning of heat stress) and the end of the experiment when the cows were under THE. Hair cortisol levels (initial hair cut as the baseline and re-grown hair) were measured using ELISA method. Body temperature (BT) was measured twice daily at 7 body points of cows including rectum, vagina, hip, udder, rumen-side (flank), ear, and forehead using non-contact forehead infrared thermometer (infrared gun having two modes: inner and skin) on the $7 \mathrm{~d}$ of the beginning and the last $7 \mathrm{~d}$ of the experiment at 1000 and $1400 \mathrm{~h}$. Statistical analyses were carried out using the MIXED model of SAS as repeated measurements. The intra-assay and inter-assay coefficients of variations for hair cortisol measurements were 3.15 and 10.05, respectively. Hair cortisol (HC) levels were not different within the two groups in both Exps. $(\mathbf{P}>\mathbf{0 . 0 5})$; however, $\mathrm{HC}$ level was lower $(\mathbf{P}<\mathbf{0 . 0 0 0 1})$ prior to temperature-humidity exposure (THE). Results of Exp. 1 showed that vagina inner temperature was higher $(\mathrm{P}=0.041)$ and rectal temperature tended to be higher $(\mathrm{P}=\mathbf{0 . 0 8 3})$ in the $\mathrm{HF}$ compared to the $\mathrm{LF}$ group. The inner ear temperature was lower and ear skin temperature was higher $(\mathrm{P}=\mathbf{0 . 0 3 2})$ in the $\mathrm{HF}$ compared to the $\mathrm{LF}$ group. Forehead inner temperature was higher $(\mathrm{P}=\mathbf{0 . 0 4 8})$ in the $\mathrm{LF}$ group than in the HF group while forehead skin temperature was lower in the $\mathrm{HF}$ group $(\mathrm{P}=\mathbf{0 . 0 4 1})$. No differences were observed in the hip, udder and rumen-side (flank) temperature (both in body and skin) between the HF and LF group ( $\mathrm{P}=\mathbf{0 . 0 1 2}$ ). In Exp. 2, no temperature differences were observed at all of the body points, inner and skin, between the two groups $(\mathrm{P}>\mathbf{0 . 0 5})$. However, the skin temperature in the $2 \mathrm{hWD}$ groups tended to be higher than in the FAW group $(\mathrm{P}=\mathbf{0 . 0 9 3})$. Conclusions drawn
\end{abstract}


indicate the beneficial use of measuring BT at different body points of the cow in addition to RT under THE.

Key words: thermal-humidity exposure, body temperature, dairy cows, forage level, hair cortisol, water deprivation

Abbreviations: BT, body temperature; BW, body weight; CP, crude fiber; DM, dry matter; DIM, days in milk; EE, ether extract; Exp., experiment; FAW, free access to water; $\mathrm{F}: \mathrm{C}$, forage:concentrate; $\mathrm{HC}$, hair cortisol; $\mathrm{NDF}$, neutral detergent fiber; NFC, non-fiber carbohydrates; NFE, nitrogen free extract; OM, organic matter; RT, rectal temperature; THE, thermal-humidity exposure; THI, temperature-humidity index; TMR, total mixed ration; $2 \mathrm{hWD}, 2$ hour water deprivation.

The measurement of body temperature (BT), particularly the rectal temperature (RT) as its representative, is a common method used in the evaluation of cow's wellbeing in dairy farms. However, in most cases, single assessment of RT may not be sufficient to evaluate BT (De et al., 2017; Ammer et al., 2016 a, b). Thus, measurements of BT at different body points might be necessary to provide better insights for cow BT evaluations. In addition, the BT may vary due to different factors, one of which is thermal-humidity exposure (THE) that has been reported by several studies (De et al., 2017; Lee et al., 2016; Ammer et al., 2016 a). Higher forage ratio may aggravate the BT increase due to producing a higher heat increment and higher rumen activity. In addition, the relationship between dry matter intake and water consumption particularly following feeding has been documented as of late (Ghassemi Nejad et al., 2016; Forbes, 1993; Beede and Collier, 1986; Conrad, 1985). Thus, higher BT and stress conditions (its indicator as a chronic stress, hair cortisol) have been hypothesized with different forage ratio during extensive THE. Therefore, temperature responses in Holstein dairy cows fed with different forage:concentrate ratio under THE need to be investigated (Exp. 1).

The BT is a beneficial management tool to be used as it shows any possible internal diseases, which can result in fever, which in turn impairs animal welfare, and consequently the production of animals. Measuring BT at various body points, not only the rectal temperature (RT) in dairy cows may be used as a developmental tool to improve our understanding of the effects of THE. Heat stress is another factor that can influence BT (Ghassemi Nejad et al., 2014 c), maintenance requirements, metabolic processes, feed efficiency, milk yield (Ghassemi Nejad et al., 2015), reproductive efficiency, behavior and disease incidence (Tucker et al., 2007; Ghassemi Nejad et al., 2015, 2017). High yielding dairy cows are more susceptible to water scarcity than small ruminants (Ghassemi Nejad et al., 2017 c; Marai et al., 2007; Casamassima et al., 2008). Cows may consume about $50 \%$ of their daily water intake within $1 \mathrm{~h}$ following milking (Beede, 1992; NRC, 2001). Peak of water intake for cows occurs during the hours when feed intake is greatest (Beede, 1992). In addition, water scarcity may intensify the effects of heat stress (Ghassemi Nejad et al., 2014 $a, b, 2015)$ due to the fact that water regulation in the body is vital for dissipation 
of heat during THE. Additionally, in other studies in our laboratory we observed $3 \mathrm{~h}$ water deprivation following feeding may act as a source of stressor by increasing wool cortisol in ewes under heat stress conditions (Ghassemi Nejad et al., 2014 a, 2017 a). Thus, the effects of water deprivation following feeding, particularly $2 \mathrm{~h}$ on BT at different sites of the body need some more insights (Exp. 2).

Moreover, hair cortisol measurements have recently been suggested to define stressor influence, THE, for prolonged period (Ghassemi Nejad et al., 2014 a, 2017 a, b). Despite the common use of RTs, there is a lack of scientific evidence explaining the value or significance of measuring the RT as a diagnostic tool to identify infectious diseases (Benzaquen et al., 2007) and production performance (Rejeb et al., 2016) in dairy cattle in the postpartum period. Thus, the measurements of BTs, inner and skin, at different body points of cows can provide insights on how possibly forage ratios and water deprivation intensify stress in dairy cows under THE. Therefore, this study was carried out to address both hypotheses. The study was designed to investigate the body inner and skin temperature responses at 7 body points of cows and embedded hair cortisol level as a well-established, precise, and reliable indicator of chronic stress in dairy cows under THE.

\section{Material and methods}

\section{Experimental design and grouping}

This study, including two experiments (Exp.), was conducted between July and September 2012 and 2013 for 64 d and 74 d, respectively. The Exps. were carried out at two sites, Naju and Daejeon, Republic of Korea. The experimental procedure and methods were approved by the animal welfare and ethics authority of Kangwon National University, Chuncheon, Korea.

In Exp. 1, twenty multiparous Holstein dairy cows (10 cows per group; $90 \pm 30$ DIM; $37.2 \pm 1.71 \mathrm{milk} / \mathrm{d}, 620 \pm 75 \mathrm{~kg} \mathrm{BW})$ were assigned to two different forage:concentrate ratios. The low forage (LF) group ratio was 44:56 and the high forage (HF) group ratio was 56:44. The animals were housed in a sheltered drylot facility with ad libitum access to water. Feed was provided as TMR (Table 1). Feed requirements were calculated based on NRC requirements of dairy cattle (NRC, 2001). Chemical compositions of feed, including DM, Ash, CP, and EE were analyzed using AOAC (1990). Acid detergent fiber (ADF) and neutral detergent fiber were analyzed using the method of Van Soest et al. (1991).

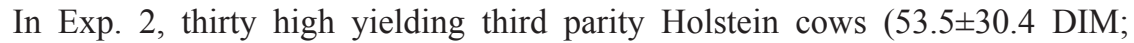
$41.7 \pm 1.51 \mathrm{milk} / \mathrm{d}, 650 \pm 53 \mathrm{~kg} \mathrm{BW}$ ), were assigned to two groups in 6 pens with 5 cows in each pen. The groups included free access to water (FAW) and $2 \mathrm{~h}$ water deprivation following feeding (2hWD). This was carried out according to a completely randomized design for 74 days. The cows were housed in a roofed shelter equipped with concrete pens confined with metal and bedded with dry manure for comfort $\left(4.5 \mathrm{~m}^{2}\right.$ per cow). Metal automatic roofs covered the barn and were open when there was no rain. The cows were fed in mangers and each pen was 
equipped with separate water through. Data from four cows (two from each group) was subjected to withdrawal from the Exp. due to their serious illnesses. The feed was provided as a TMR (Table 2). Feed requirements were calculated based on NRC requirements of dairy cattle (NRC, 2001). The feed was offered three times daily at 0800, 1300, and $2000 \mathrm{~h}$. Chemical compositions of feed, including DM, Ash, CP, and EE were analyzed using AOAC (1990). Acid detergent fiber (ADF) and neutral detergent fiber were analyzed using the method of Van Soest et al. (1991). Water was available free of choice to the FAW group; however, it was provided following feeding time at 1000, 1500 and $2200 \mathrm{~h}$ for the $2 \mathrm{hWD}$ group. Prior to and following the water deprivation time, cows were given free access to water.

Table 1. Feed and chemical composition of diet for Holstein lactating cows (Naju location, Exp. 1)

\begin{tabular}{lc}
\multicolumn{1}{c|}{ TMR composition } & $\%$ of DM \\
\hline Forage & 26.2 \\
BIRG silage & 29.6 \\
mixed hay + straw & \\
Concentrate & 3.4 \\
beet pulp & 4.5 \\
whole cottonseed & 3.1 \\
corn flour & 32.4 \\
commercial concentrate & \\
Chemical composition (\% of DM) & 66.0 \\
dry matter & 8.5 \\
ash & 16.0 \\
crude protein & 3.7 \\
ether extract & 16.2 \\
crude fiber & 46.4 \\
neutral detergent fiber & 25.4 \\
acid detergent fiber & 52.5 \\
non-fiber carbohydrate & 66.5 \\
TDN & 1.5 \\
NE (Mcal/kg) & \\
\hline
\end{tabular}

BIRG: Barley Italian ryegrass; mixed hay included: alfalfa hay, timothy, oat; straw included: Italian ryegrass, tall fescue hay, and klein ryegrass hay.

\section{Hair cortisol sampling and assay}

All of the animals were subjected to having the hair cut from their foreheads at the same time $(1200 \mathrm{~h})$ at the beginning and the end (after 2 months) of the experiment from June to September when the cows were under THE. The re-grown hair was subjected to hair cortisol (HC) assay as fully described by Ghassemi Nejad et al. (2014 a, $2017 \mathrm{a}, \mathrm{b})$ and the assay kit was used according to the manufacturer's guidance (Salimetrics, high sensitivity salivary cortisol, enzyme immunoassay kit, State College, PA, USA). 
Table 2. Ingredients and chemical composition of TMR (Daejeon location, Exp. 2)

\begin{tabular}{|c|c|}
\hline TMR composition & $\%$ of DM \\
\hline \multicolumn{2}{|l|}{ Forage } \\
\hline timothy & 17.9 \\
\hline mixed hay & 14.3 \\
\hline alfalfa & 1.8 \\
\hline \multicolumn{2}{|l|}{ Concentrate } \\
\hline commercial concentrate & 26.8 \\
\hline beet pulp & 6.4 \\
\hline whole cottonseed & 6.4 \\
\hline corn flour & 1.4 \\
\hline citrus pulp & 25.0 \\
\hline \multicolumn{2}{|l|}{ Chemical composition } \\
\hline dry matter & 74.4 \\
\hline crude protein & 15.9 \\
\hline neutral detergent fiber & 41.7 \\
\hline acid detergent fiber & 28.3 \\
\hline organic matter & 89.9 \\
\hline ether extract & 2.6 \\
\hline ash & 10.1 \\
\hline TDN & 68.9 \\
\hline $\mathrm{NE}_{1}(\mathrm{Mcal} / \mathrm{kg})$ & 1.83 \\
\hline
\end{tabular}

Commercial concentrate made by feed company; mixed hay included: blue grass, alfalfa, timothy and oat; citrus pulp, calculated compositions: $\mathrm{DM}=13.5, \mathrm{CP}=9.6, \mathrm{Ash}=5.8, \mathrm{EE}=1.6, \mathrm{NDF}=27.6, \mathrm{ADF}=25.8$.

\section{Body temperature measurements}

Body temperature (BT) was measured at 7 body points of cows including rectum, vagina, hip, udder, rumen-side (flank), ear, and forehead using non-contact forehead infrared thermometer called infrared gun (having two modes; inner and skin; CEM, Rev. 090709, Shenzhen Everest Machinery Industry co. Ltd., China) on the $7 \mathrm{~d}$ of the beginning and the last $7 \mathrm{~d}$ of each Exp. twice daily at sampling days at 1000 and $1400 \mathrm{~h}$. The infrared gun was designed to have specifications include the inner temperature of 32.0 to $42.5^{\circ} \mathrm{C}\left(89.6\right.$ to $\left.108.5^{\circ} \mathrm{F}\right)$, and the skin temperature range of 0 to $60^{\circ} \mathrm{C}\left(32\right.$ to $\left.140^{\circ} \mathrm{F}\right)$, measuring distance of 5-15 cm (2-5.9 inch) and high resolution. In both Exps. the same person was responsible for all the data collection to assure consistency when shooting the gun in order to decrease the chance for any possible human errors.

\section{Temperature-humidity index}

The highest daytime temperatures reached around $35^{\circ} \mathrm{C}$ and $38^{\circ} \mathrm{C}$ followed by the relative humidity of $86 \%$ and $91 \%$ whereas the lowest temperature and humidity were $18^{\circ} \mathrm{C}$ and $22^{\circ} \mathrm{C}$ followed by the relative humidity of $63 \%$ and $65 \%$ for Exps. 1 
and 2, respectively (Figure 1 and Figure 2). Temperature and relative humidity were monitored at hourly intervals throughout the trial by using a temperature-humidity data logger device (CEM-DT-172, No. 11048007, Shenzhen, China). Average temperature-humidity index (THI) in the farm was equal to or over 76 and 80 for Exps. 1 and 2 throughout the study. This was calculated using the equation of Ravagnolo et al. (2000) which defines thermal-humidity conditions. The formula used for the THI calculation is as follows:

$$
T H I=(1.8 t+32)-[(0.55-0.0055 R H) \times(1.8 t-26)]
$$

Where $t$ is the air temperature $\left({ }^{\circ} \mathrm{C}\right)$ and $R H$ is the relative humidity $(\%)$. The $T H I$ values obtained indicated the following: $\angle 71^{\circ} \mathrm{F}\left(21.6^{\circ} \mathrm{C}\right)=$ absence of heat stress; $72^{\circ} \mathrm{F}\left(22.2^{\circ} \mathrm{C}\right)$ to $<79^{\circ} \mathrm{F}\left(26.1^{\circ} \mathrm{C}\right)=$ mild heat stress: $80^{\circ} \mathrm{F}\left(26.6^{\circ} \mathrm{C}\right)$ to $<89^{\circ} \mathrm{F}$ $\left(31.6^{\circ} \mathrm{C}\right)=$ moderate heat stress and $90^{\circ} \mathrm{F}\left(32.2^{\circ} \mathrm{C}\right)$ and above $=$ severe heat stress (Armstrong, 1994).

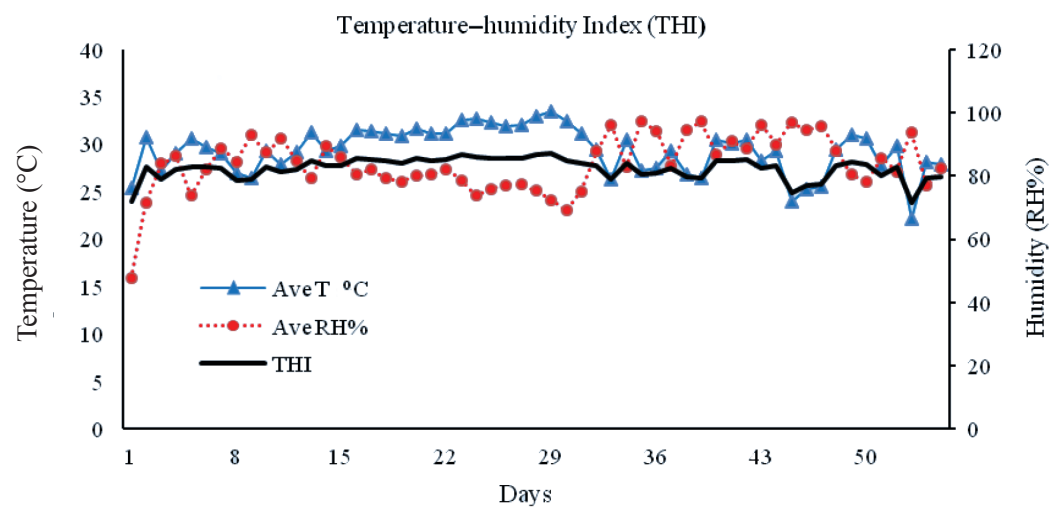

Figure 1. Average daily pattern (hourly intervals) of temperature-humidity index (THI) during Exp. 1

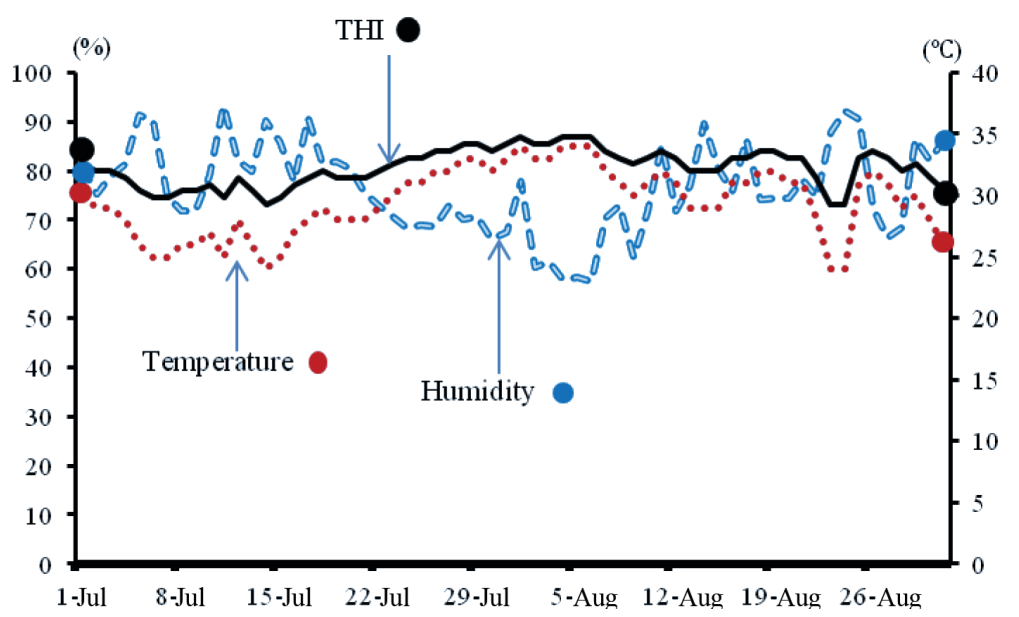

Figure 2. Average daily pattern (hourly intervals) of temperature-humidity index (THI) during Exp. 2 


\section{Statistical analysis}

Data were analyzed using repeated measures analysis and MIXED procedure of SAS (2001, version 9.0; SAS institute Inc. Cary NC, USA) and the means were compared for significance by Tukey's test at $\mathrm{P}<0.05$. The statistical differences were considered significant at $\mathrm{P}<0.05$ and differences among means with $0.05<\mathrm{P}<0.10$ were accepted as representing tendencies to differences. The statistical model used for analyses was:

where:

$$
Y_{i j k l}=\mu+\alpha_{i}+d_{i j}+W_{k}+T_{l}+(\alpha T)_{i l}+e_{i j k l}
$$

$Y_{i j k l}=$ the observation for the trait,

$\mu=$ overall mean,

$\alpha_{i}=$ the effect of group,

$d_{i j}=$ random effect of animal,

$W_{k}=$ initial body weight,

$T_{l}=$ the effect of time,

$(\alpha T)_{i l}=$ interaction of group $\times$ time,

$e_{i j k l}=$ the residual effect.

Variance and covariance assumption structures including auto regressive (1) $(\mathrm{AR}(1))$, unstructured (UN), and compound symmetry (CS) were tested, then $\mathrm{AR}(1)$ as the best covariance structure selected when appropriate. The interaction of group $\times$ time was not significant.

\section{Results}

No differences in hair cortisol (HC) level $(\mathrm{P}>0.05)$ under thermal-humidity exposure (THE), were found in both Exps. (Table 3). However, prior to THE, HC level was higher $(\mathrm{P}<0.05)$ in the low forage (LF) group than in the high forage (HF) group.

The differences between HC levels prior to and post THE (Table 3) were highly significant $(\mathrm{P}<0.0001)$ where the $\mathrm{HC}$ levels in both Exps. showed higher values under THE than prior to its beginning.

At the beginning of Exp. 2, prior to the application of the groups, no significant differences $(\mathrm{P}>0.05)$ were observed on inner and skin temperature at the 7 body points of cows.

At the end of the experiment, vagina inner temperature was higher $(\mathrm{P}=0.041)$ in the HF group compared with the LF group (Figure 3). Rectal temperature (RT) was not different $(\mathrm{P}>0.05)$ between the two groups (Figure 3$)$.

The inner ears temperature was lower $(\mathrm{P}=0.041)$ and the ear skin temperature was higher $(\mathrm{P}=0.032)$ in the HF group when compared to the LF group (Figure 3 ). The forehead inner temperature was higher $(\mathrm{P}=0.048)$ in the LF group, while the forehead skin temperature was lower $(\mathrm{P}=0.041)$ in the HF group (Figure 3$)$. No differences $(\mathrm{P}=0.121)$ were observed in the hip, udder and rumen-side (flank) temperature (both in inner and skin) between the HF and LF group (Figure 3). 
Table 3. Effects of high- and low-forage diet and water deprivation on hair cortisol level in Holstein lactating cows prior to and under thermal-humidity exposure

\begin{tabular}{l|c|c|c|c}
\hline Groups & $\begin{array}{c}\text { Hair cortisol } \\
\text { (pg/mg of hair) } \\
\text { prior to THE }\end{array}$ & $\begin{array}{c}\text { Hair cortisol } \\
\text { (pg/mg of hair) } \\
\text { under THE }\end{array}$ & SEM & $\begin{array}{c}\text { Non-THE vs. THE } \\
\text { (P-value) }\end{array}$ \\
\hline $\begin{array}{c}\text { Experiment 1 } \\
\text { low forage }\end{array}$ & $3.8 \mathrm{a}$ & 13.6 & 1.3 & $<0.0001$ \\
$\quad$ high forage & $2.3 \mathrm{~b}$ & 14.2 & 0.9 & $<0.0001$ \\
Experiment 2 & 6.3 & & & \\
FAW & 6.5 & 24.2 & 1.7 & $<0.0001$ \\
2hWD & 26.2 & 1.8 & $<0.0001$ \\
\hline
\end{tabular}

Low forage: $\mathrm{F}: \mathrm{C}$ ratio $=44: 56$, high forage: $\mathrm{F}: \mathrm{C}$ ratio $=56: 44$, free access to water $(\mathrm{FAW}), 2$ hour water deprivation (2hWD) following feeding.

$\mathrm{a}, \mathrm{b}$ - values within a column with different letters differ significantly at $\mathrm{P}<0.05$.

All samples were derived from the same large pool of hair.

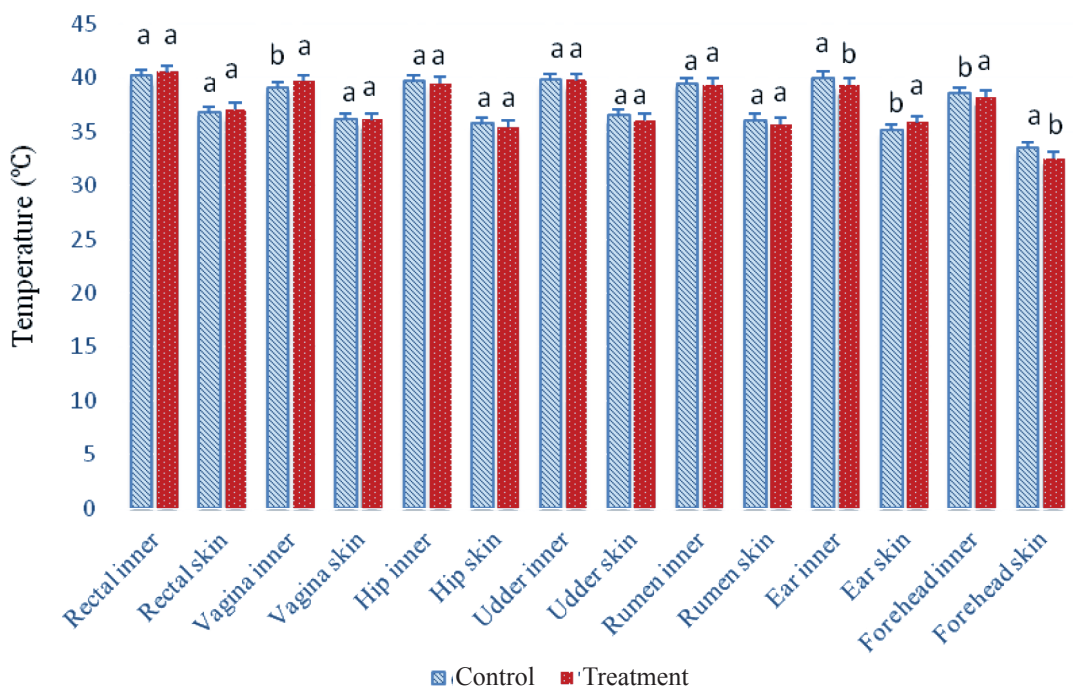

Figure 3. Effects of high- and low-forage diet on body inner and skin temperature in dairy Holstein cows under thermal-humidity exposure

In Exp. 2, no differences were observed at all of the body points temperature, inner and skin, between the two groups $(\mathrm{P}>0.05)$. However, skin temperature in the $2 \mathrm{hWD}$ groups tended to be higher ( $\mathrm{P}=0.093$ ) than in the FAW group (Figure 4). 


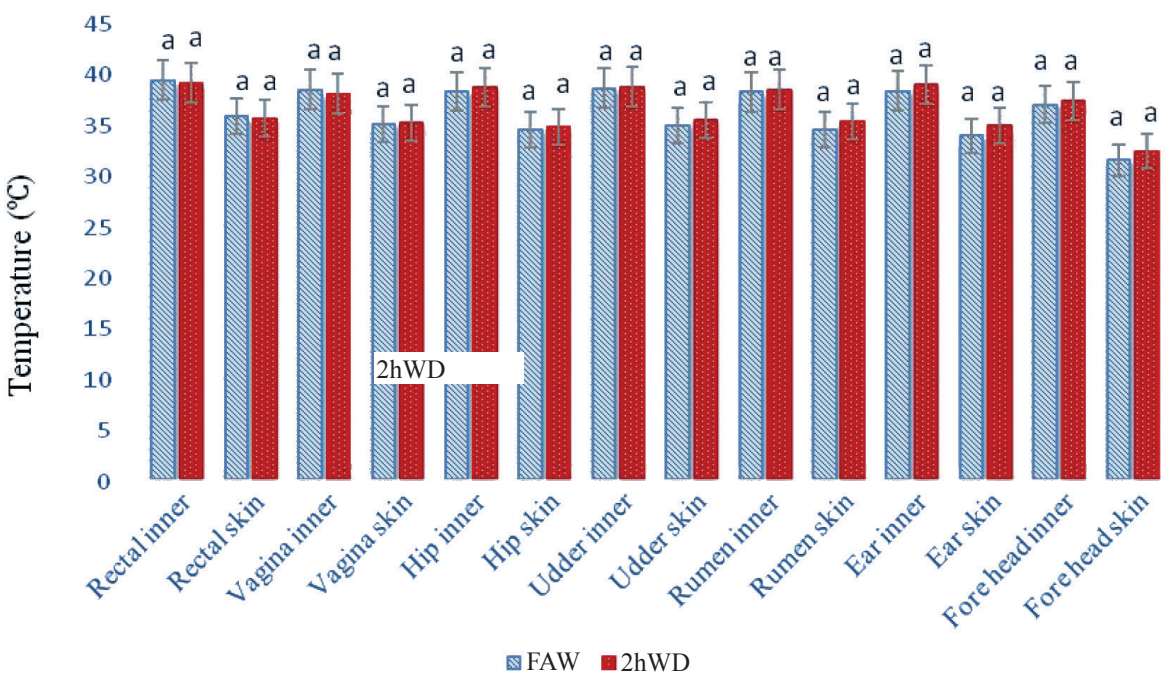

Figure 4. Effects of water deprivation on body inner and skin temperature in dairy Holstein cows under thermal-humidity exposure (Exp. 2)

\section{Discussion}

No differences in hair cortisol (HC) level under thermal-humidity exposure (THE) in both Exps. are in contrast with our expectation. This indicates that different forage levels up to $10 \%$ and water deprivation following feeding up to $2 \mathrm{~h}$ were not strongly influential to provoke the severity of heat stress in groups during THE. On the other hand, higher HC level in the LF group prior to THE may demonstrate that while a 10\% different forage level could not affect the stress level, herein $\mathrm{HC}$, it may affect the $\mathrm{HC}$ level during comfort zone (thermo-neutral zone) in dairy cows. A higher forage level during THE is supposed to increase BT (Forbes, 1993; Beede and Collier, 1986; Conrad, 1985) which was observed in this Exp.; however, the small excess in BT did not result in higher stress levels. This could be illustrated in higher $\mathrm{HC}$ level during prolonged THE. The low difference in $\mathrm{F}: \mathrm{C}$ ratio in the present experiment may explain non-significances of BT in different parts of animal's body. The experiment, however, was designed to have $20 \%$ difference in forage ratio between LF and HF group. Practically dealing with farmers, based on on-farm procedure, we could not achieve our goal to make F:C ratio up to 60:40 and 40:60 for HF and LF group, respectively.

The results of the present study (Table 3) illustrated that THE highly increases the cortisol levels as an indicator of prolonged heat stress conditions in dairy cows, regardless of the groups $(\mathrm{P}<0.0001)$. The role of high ambient temperature and high relative humidity on elevating hair cortisol level of dairy cows is promising (Ghassemi Nejad et al., 2017 a; De et al., 2017; Lee et al., 2016; Ammer et al., 2016 a). The 
fact that prior to the beginning of the Exps. cows were not under THE, may explain lower levels of $\mathrm{HC}$ in both groups prior to the THE.

The HC levels in Exp. 2 showed approximately double values when compared to the HC levels in Exp. 1. The reason could be attributed to the fact that higher milk yield of cows in Exp. 2 compared with Exp. 1 resulted in higher vulnerability of cows to stress, and thus, higher HC levels. Also, the THI showed higher values in Exp. 2 compared with Exp. 1. This may cause higher HC levels in cows in Exp. 2.

RT is a sensitive indicator of thermal balance and may be used to assess the negative effects of hot and humid environments on growth, lactation, and reproductive rates of dairy cows (West, 1999; Rejeb et al., 2016). However, it has been shown that an increase of $1^{\circ} \mathrm{C}$ or less in RT is enough to reduce intake and production in dairy cows (Johnson et al., 1963; Rejeb et al., 2016). Elevated RT was not always observed in endotoxic cows (Andersen, 2003), thus providing a possible explanation as to why cows failed to exhibit an elevated temperature when measured twice daily under THE in this Exp. The method most commonly used to identify sick dairy cows in the postpartum period is measuring rectal temperature (Smith and Risco, 2005). Moreover, measuring RT for 5 to $10 \mathrm{~d}$ after calving has received attention more recently because of ease of implementation and low cost (Kristula et al., 2001) and has been incorporated into standard operating protocols for the cow's management and disease recognition. A possible explanation for higher vagina inner temperature in HF group could be that higher forage ration may increase the core BT which is reflected on vagina inner temperature. Most professionals define fever when BT exceeds a predefined threshold. In this regard, usually a single instance of a temperature above the threshold value is considered as an indication of illness. Threshold values of $39.4^{\circ} \mathrm{C}$ and $39.7^{\circ} \mathrm{C}$ (Smith and Risco, 2005; Benzaquen et al., 2007; Wagner et al., 2007) distinguished between healthy cows and cows suffering from an infectious-related disease process. The reason behind lower inner ears temperature and the higher ears skin temperature between the HF group and LF group remains unknown at this time.

Ghassemi Nejad et al. (2014 a) reported higher wool cortisol in ewes exposed to water deprivation for 3 hours following feeding. Despite water deprivation, it was reported (Ghassemi Nejad et al., $2017 \mathrm{~b}$ ) that water addition to TMR up to 50\% and $60 \%$ of DM could not affect wool cortisol in ewes under heat stress conditions. Higher skin temperature in the 2hWD group than the FAW group demonstrates that heat dissipation was higher from the surface of the body in 2hWD group as a result of intensifying THE stress by water deprivation. Increased RT signifies lack of thermal balance and increased water intake to replace increased evaporative losses (Mohammed and Johnson, 1984; Rejeb et al., 2016). Water is arguably the most important nutrient for dairy cows and should be available in adequate amounts, especially during heat stress (Ghassemi Nejad et al., 2014 a, b, 2017 b). Furthermore, it has been reported that body temperature is usually maintained by the thermoregulatory system within $1^{\circ} \mathrm{C}$ of its normal temperature under ambient conditions that do not impose severe heat stress (Berman et al., 1985). Restriction of water availability may have negative influences on a cow's well-being and performance (West, 2003). In addition, water deprivation for any reason can act as a stressor. This may intensify the severity of stress, particularly during heat stress (Ghassemi Nejad et al., 2014 a, b, 
$2017 \mathrm{~b}$ ). In this study, however, we concluded that $2 \mathrm{~h}$ water deprivation following feeding is not influential enough to intensify THE stress indicator herein body temperature. This study suggests the beneficial uses of measuring BT at different body points in addition to RT to identify if cows are really stressed under THE. Finally, it should be noted that a lower temperature in some of the locations in Exp. 1 compared with Exp. 2 could be due to two reasons. The first being higher THI in Exp. 1 (around 76) compared with Exp. 2 (around 80). This could influence some locations of the body that are more exposed to environmental temperatures directly. Another reason can be attributed to the nature of the treatments in Exp. 1 and Exp. 2 which suggests that water deprivation could act as a stronger cause of an increase in body temperature. However, the influences of the aforementioned factors, particularly in some specific locations in the body of lactating cows need further research.

\section{Conclusions}

From the results of these two consecutive studies, we suggest the benefit of the BT measurements at different body points in addition to RT as indicators of THE stress. According to our data and in order to have a better understanding of BT, we suggest the measurement of temperature not only from rectum but vagina, forehead, and ears of the cattle. Further research with higher difference in $\mathrm{F}: \mathrm{C}$ ratios and water deprivation time is needed to investigate the embedded hair cortisol as an indicator of chronic stress conditions, herein THE stress and BT responses in cattle under heat stress conditions. We conclude that higher forage ratio of approximately $10 \%(\mathrm{~F}: \mathrm{C}=$ 56:44) and water deprivation following feeding for 2 hours are not influential enough to increase hair cortisol as the long-term indicator of stress conditions in dairy cows; however, heat stress conditions act as a strong stressor by increasing hair cortisol levels in both groups compared with thermo-neutral zone conditions.

\section{Acknowledgment}

This study has been performed with the support of a research grant of Kangwon National University in 2016 (project number: 520160154). The cortisol analysis, however, was supported by Basic Science Research Program through the National Research Foundation of Korea (NRF) funded by the Ministry of Education (Project number: 2018051321, ID: 2018R1D1A1A02051321). The authors thank Jennette B.A. Cabibi (Elmira College, SUNY University, USA) for her contribution for English proof-reading of the manuscript prior to submission.

\section{Conflict of interest}

The authors declare no conflict of interest in this work.

\section{References}

A m m e r S., L a m bert z C., Ga u ly M. (2016 a). Is reticular temperature a useful indicator of heat stress in dairy cattle? J. Dairy Sci., 99: 10067-10076.

A mmer S., Lambertz C., Gauly M. (2016 b). Comparison of different measuring methods 
for body temperature in lactating cows under different climatic conditions. J. Dairy Res., 83: $165-172$.

A n d e r s e n P.H. (2003). Bovine endotoxicosis: Some aspects of relevance to production diseases. Acta Vet. Scan., 98 (Suppl.): 141-155.

AOAC (1990). Official Methods of Analysis, 15th ed. Association of Official Analytical Chemists, Washington, DC.

Armstrong D.V. (1994). Heat stress interactions with shade and cooling. J. Dairy Sci., 77: 2044-2050.

B e e d e D.K. (1992). Water for dairy cattle. Chapter 28. In: Large dairy herd management, H.H. Van Horn, C.J. Wilcox (eds.). American Dairy Association Publ., Champaign, IL, USA, pp. 260-271.

B e e d e D.K., C o 11 i e r R.J. (1986). Potential nutritional strategies for intensively managed cattle during thermal stress. J. Anim. Sci., 62: 543-554.

B enzaquen M.E., R is co C.A., A rchbald L.F., Melendez P., Thatcher M.J., That c h e r W.W. (2007). Rectal temperature, calving-related factors, and the incidence of puerperal metritis in postpartum dairy cows. J. Dairy Sci., 90: 2804-2814.

B erman A., Folman Y.M., Ka im M., Mamen M., Herz Z., Wolfenson D., Arieli A., Graber Y. (1985). Upper critical temperatures and forced ventilation effects for high-yielding dairy cows in a tropical climate. J. Dairy Sci., 68: 1488-1495.

Casamassima D., Pizzo R., Palazzo M., D'Alessandro A.G., Martemucci G. (2008). Effect of water restriction on productive performance and blood parameters in comisana sheep reared under intensive condition. Small Rumin. Res., 78: 169-175.

Con ra d J.H. (1985). Feeding of farm animals in hot and cold environments. In: Stress Physiology in Livestock 1, Yousef M.K. (ed.). CRC Press, Boca Raton, FL, pp. 205-226.

D e K., K u m a r D., S a x e n a V.K., N a q vi S.M.K. (2017). Study of circadian rhythmicity of physiological response and skin temperature of sheep during summer and winter in semi-arid tropical environment. Physiol. Behav., 169: 16-21.

F o r b e s J.M. (1993). Voluntary feed intake. In: Quantitative Aspects of Ruminant Digestion and Metabolism, Forbes J.M., France J. (eds.). CAB International, Devon, pp. 479-494.

Ghassemi Nejad J., Lohakare J.D., West J.W., S ung K.I. (2014 a). Effects of water restriction after feeding during heat stress on nutrient digestibility, nitrogen balance, blood profile and characteristics in Corriedale ewes. Anim. Feed Sci. Technol., 193: 1-8.

Ghassemi Nejad J., Lohakare J.D., Son J.K., Kwon E.G., West J.W., Sung K.I. (2014 b). Wool cortisol is a better indicator of stress than blood cortisol in ewes exposed to heat stress and water restriction. Animal, 8: 128-132.

Ghassemi Nejad J., Kim B.W., Lohakare J.D., West J.W., Lee B.H., Ji D.H., P eng J.L., S ung K.I. (2014 c). Temperature responses in Holstein lactating cows fed with different forage: concentrate ratio under heat stress condition. Abstract. Proc. 48th Congress of the international Society for Applied Ethology, Spain, Vitoria Gasteiz. p. 172.

Ghassemi Nejad J., Lohakare J.D., West J.W., Sung K.I. (2015). Effects of water restriction following feeding on nutrient digestibilities, milk yield and composition and some blood hormones in lactating Holstein cows under heat stress condition. Ital. J. Anim. Sci., 14: 479-483.

Ghas semi Nejad J., Sung K.I., Lee B.H., P eng J.L., Kim J.Y., Oh S.M., Che mere B., $\mathrm{K}$ i m B.W. (2016). Effects of adding water to total mixed ratio on water consumption, nutrient digestibility, wool cortisol, and blood indices in Corriedale ewes under hot and humid conditions. Abstract. Proc. JAM (Joint Annual Meeting), 19-23.07.2016, Salt City, UT, pp. 818. Poster presentation.

Ghas semi Nejad J., Kim B.W., Lee B.H., Sung K.I., Ki m J.Y. (2017 a). Effects of water addition to total mixed ration on water intake, nutrient digestibility, wool cortisol and blood indices in Corriedale ewes. Asian-Australas. J. Anim. Sci., 30: 1435-1441.

Ghas s e mi Neja d J., K i m B.W., L e e B.H., S ung K.I. (2017 b). Coat and hair color: hair cortisol and serotonin levels in lactating Holstein cows under heat stress conditions. Anim. Sci. J., 88: 190-194.

Ghas s e mi N e j a d J., S ung K.I. (2017 c). Behavioral and physiological changes during heat stress in Corriedale ewes exposed to water deprivation. Biol. Rhythm Res., 49: 382-391. 
Johnson H.D., Rag s dale A.C., B erry I.L., Shanklin M.D. (1963). Temperature-humidity effects including influence of acclimation in feed and water consumption of Holstein cattle. University of Missouri, Research Bulletin, No. 846.

Kris tula M., S m i th B.I., S i m e on e A. (2001). The use of daily postpartum rectal temperatures to select dairy cows for treatment with systemic antibiotics. Bovine Pr., 35: 117-125.

L e e Y., B o k J.D., L e e H.J., K i m D., L e e I., K a n g w S.K., C h o i Y.J. (2016). Body temperature monitoring using subcutaneously implanted thermo-loggers from Holstein steers. Asian-Australas. J. Anim. Sci., 29: 299-306.

M a r a i I.F.M., E 1 - D a r a w a n y A.A., F a d i e 1 A., A b d e 1 - H a f e z M.A.M. (2007). Physiological traits as affected by heat stress in sheep - a review. Small Rumin. Res., 71: 1-12.

Moham med M.E., John s on H.D. (1984). Effect of growth hormone on milk yields and related physiological functions of Holstein cows exposed to heat stress. J. Dairy Sci., 68: 1123-1133.

National Research Council (2001). Nutrient Requirements of Dairy Cattle. 7th rev. ed. National Academy Press, Washington, DC, USA.

Ravagnolo O., Misztal I., Hoogenboom G. (2000). Genetic component of heat stress in dairy cattle, development of heat index function. J. Dairy Sci., 83: 2120-2125.

R ej eb M., S adraoui R., Najar T., B en M'rad M. (2016). A complex interrelationship between rectal temperature and dairy cows' performance under heat stress conditions. Open J. Anim. Sci., 6: 24-30.

S m ith B.I., R is c o C.A. (2005). Management of periparturient disorders in dairy cattle. Vet. Clin. North Am. Food Anim. Pract., 21: 503-521.

Tucker C.B., R o ger s A.R., Shutz K.E. (2007). Effect of solar radiation on dairy cattle behaviour, use of shade and body temperature in a pasture-based system. Appl. Anim. Behav. Sci., 109: $141-154$.

Van S o e s t P.J., R o berts o n J.B., L e w is B.A. (1991). Methods for dietary fiber, neutral detergent fiber, and non-starch polysaccharides in relation to animal nutrition. J. Dairy Sci., 74: 3583-3597.

W a g n e r S.A., S c h i m e c k D.E., C h e n d F.C. (2007). Body temperature and white blood cell count in postpartum dairy cows. Bovine Pr., 42: 18-26.

We s t J.W. (1999). Nutritional strategies for managing the heat-stressed dairy cow. J. Anim. Sci., 77: 21-35.

We s t J.W. (2003). Effects of heat-stress on production in dairy cattle. J. Dairy Sci., 86: 2131-2144.

Received: 17 II 2018

Accepted: 12 IX 2018 